\title{
Monitoring potential photochemical interference in laser- induced fluorescence measurements of atmospheric OH
}

\author{
Manvendra K. Dubey, Thomas F. Hanisco, Paul O. Wennberg, and James G. Anderson \\ Department of Chemistry, Harvard University, Cambridge, MA
}

\begin{abstract}
In situ laser-induced fluorescence measurements of atmospheric $\mathrm{OH}$ are susceptible to interference from laser generated $\mathrm{OH}$, particularly in the troposphere. To quantify this interference we implement the addition of perfluoropropene, $\mathrm{C}_{3} \mathrm{~F}_{6}$, for the chemical removal of $\mathrm{OH}$ from the ambient air. The removal rate of $\mathrm{OH}$ by $\mathrm{C}_{3} \mathrm{~F}_{6}$ is determined in the laboratory using the discharge flow technique. Over the temperature range 249 to $296 \mathrm{~K}$ the rate constant is $(6.0 \pm 0.8) \times 10^{-13} \exp [(370 \pm$ 40)/T] $\mathrm{cm}^{3}$ molecule $\mathrm{e}^{-1} \mathrm{~s}^{-1}$, independent of pressure. In situ measurements using $\mathrm{C}_{3} \mathrm{~F}_{6}$ addition are performed in both aircraft-borne and ground-based experiments. These studies show that laser excitation of the ${ }^{2} \Sigma^{+}(v=1) \leftarrow{ }^{2} \Pi(v=0)$ transition (282 $\mathrm{nm}$ ) at high pulse repetition rates and low peak power can provide reliable and sensitive measurements of tropospheric $\mathrm{OH}$.
\end{abstract}

\section{Introduction}

The $\mathrm{OH}$ radical is the principal gas-phase oxidant in the troposphere, determining the atmospheric lifetime and degradation products of many gases released into the atmosphere [Crutzen, 1973]. OH oxidizes gaseous sulfur species, for example $\left(\mathrm{CH}_{3}\right)_{2} \mathrm{~S}$ and $\mathrm{SO}_{2}$, enabling the formation of aerosols that serve as cloud nuclei. These mechanisms influence the global climate and control acid rain production. $\mathrm{OH}$ also initiates the formation of photochemical smog that produces ozone in polluted urban and upper tropospheric regions. In addition, the odd hydrogen family $\left(\mathrm{HO}_{\mathrm{x}}=\mathrm{OH}, \mathrm{HO}_{2}\right.$, and $\left.\mathrm{H}\right)$ plays a significant role in determining the loss rate of stratospheric ozone. Observations indicate that catalytic ozone losses by $\mathrm{OH}$ and $\mathrm{HO}_{2}$ are prominent in the lower [Wennberg et al., 1994a] and upper [Jucks et al., 1996] stratosphere. The central role played by $\mathrm{OH}$ in regulating our atmosphere has prompted the development of precise methods for its quantitative detection [Albritton et al., 1990]. Its minute abundance, reactive nature, and the potential interferences from other species have made this task challenging.

Among the current generation of instruments, those detecting $\mathrm{OH}$ by laser-induced fluorescence (LIF) in the ultraviolet (UV) promise high sensitivity and selectivity [Crosley, 1995]. A potential interference exists, however, in atmospheric $\mathrm{OH}$ measurements using this technique. The UV laser photon has enough energy to photodissociate $\mathrm{O}_{3}$ present in the sampled air, producing $O\left({ }^{1} D\right)$. $O\left({ }^{1} D\right)$ can react with hydrogen containing molecules, principally $\mathrm{H}_{2} \mathrm{O}$ and $\mathrm{CH}_{4}$, generating $\mathrm{OH}$. This chemistry is extremely fast: $\mathrm{OH}$ can be produced and detected during the same 10 nanosecond (ns) laser pulse. Since the generation of $O\left({ }^{1} D\right)$ and the subsequent detection of laser generated

Copyright 1996 by the American Geophysical Union.

Paper number 96GL03008.

0094-8534/96/96GL-03008\$05.00
$\mathrm{OH}$ is a two photon process, the production of $\mathrm{O}\left({ }^{1} \mathrm{D}\right)$ from $\mathrm{O}_{3}$ photolysis is minimized by the use of low laser pulse energies. This design strategy was implemented in early balloon-borne LIF systems that used a high repetition rate, low peak power $\mathrm{Cu}$ vapor laser [Stimpfle et al., 1988] to detect stratospheric $\mathrm{OH}$ without photochemical interferences. On the other hand, LIF instruments using high peak power, low repetition rate lasers for tropospheric $\mathrm{OH}$ measurements can exhibit significant contamination from laser generated $\mathrm{OH}$ [Smith and Crosley, 1990].

The most common methods for LIF measurement of $\mathrm{OH}$ use laser excitation of either the ${ }^{2} \Sigma^{+}(v=0) \leftarrow{ }^{2} \Pi(v=0)$ band at 308 $\mathrm{nm}$ or the ${ }^{2} \Sigma^{+}(v=1) \leftarrow{ }^{2} \Pi(v=0)$ band at $282 \mathrm{~nm}$ and detect the fluorescence of the excited $\mathrm{OH}$ at $308 \mathrm{~nm}$. The $O\left({ }^{1} \mathrm{D}\right)$ production from $\mathrm{O}_{3}$ photolysis is two orders of magnitude lower at $308 \mathrm{~nm}$ than at $282 \mathrm{~nm}$; thus the use of the 0-0 transition lowers the possibility of $\mathrm{OH}$ generation from $O\left({ }^{1} \mathrm{D}\right)$ reactions. However, since the probe laser and fluorescence detection are both at $308 \mathrm{~nm}$, the sensitivity of the $0-0$ pumping technique is limited by the prompt scattering of the probe laser. Gating techniques can be used to minimize the laser scatter but these require low pressures ( $\sim 5$ torr) to extend the fluorescence lifetime beyond the laser pulse. The $1-0$ band at $282 \mathrm{~nm}$ can be used at both high and low pressures because the laser scatter can be removed from the fluorescence signal at $308 \mathrm{~nm}$ by optical filtering. To minimize the potential photochemical interference, the Harvard $\mathrm{HO}_{\mathrm{x}}$ instrument uses low pulse energies $(<2$ $\mu \mathrm{J} /$ pulse) at high repetition rates $(6 \mathrm{kHz})$ to pump the $1-0$ transition at $282 \mathrm{~nm}$ [Wennberg et al., 1994b]. The velocity in the duct is kept sufficiently fast $(>30 \mathrm{~m} / \mathrm{s}$ ) to ensure that each laser pulse interrogates a fresh volume of air. Nevertheless, it is important to verify the absence of laser generated $\mathrm{OH}$ in the LIF instrument for a wide range of operating conditions.

In the design of the Harvard LIF $\mathrm{HO}_{\mathrm{x}}$ instrument a method is implemented to directly monitor laser generated $\mathrm{OH}$. A reactive scrubber, perfluoropropene $\left(\mathrm{C}_{3} \mathrm{~F}_{6}\right)$, can be added to the flow in sufficient quantities to remove ambient $\mathrm{OH}$ from the sampled air by reaction in a few milliseconds (ms). The amount of $\mathrm{C}_{3} \mathrm{~F}_{6}$ added, however, is insufficient to affect the laser generated $\mathrm{OH}$ since it is created and detected in a single $10 \mathrm{~ns}$ laser pulse. Thus, $\mathrm{OH}$ measured with $\mathrm{C}_{3} \mathrm{~F}_{6}$ added provides a means of quantifying the spurious signal.

\section{The ideal OH Scrubber: $\mathrm{C}_{3} \mathrm{~F}_{6}$}

The scrubber is required to react fast enough with $\mathrm{OH}$ so that its addition in trace amounts will remove ambient $\mathrm{OH}$ in milliseconds. In the process it should not generate other radicals in order to avoid the complications of secondary chemistry. Additionally, it should not add to the hydrogen content of the air since rapid $\mathrm{OH}$ production by reaction with $\mathrm{O}\left({ }^{1} \mathrm{D}\right)$ can occur in the detection zone. This restriction excludes the use of hydrocarbons, which others have used to measure the laser gener- 


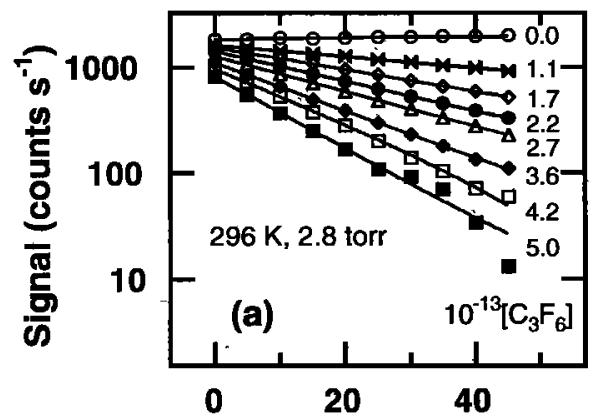

Reaction Distance (cm)

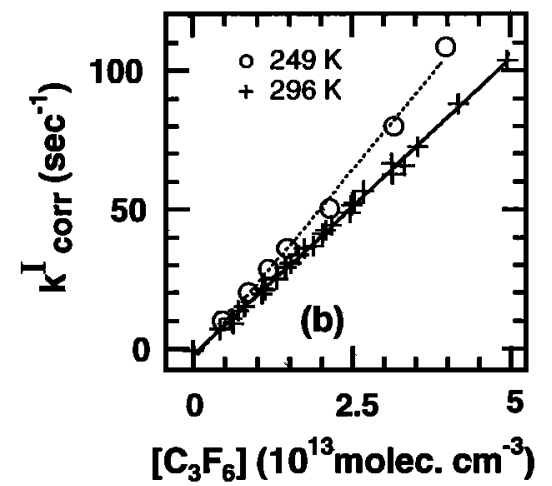

Figure 1. Kinetics of $\mathrm{OH}+\mathrm{C}_{3} \mathrm{~F}_{6}$ : (a) The $\mathrm{OH}$ fluorescence signal is plotted on a log scale against the reaction distance for experiments at 2.8 torr and $296 \mathrm{~K}$. At right are the concentrations of $\mathrm{C}_{3} \mathrm{~F}_{6}$. Distance is converted to time using the bulk flow velocity (v). The $\mathrm{OH}$ concentration is kept below $10^{11}$ molecules $\mathrm{cm}^{-3}$ to prevent $\mathrm{OH}$ regeneration. (b) The plot of the corrected decay rates $k_{\text {corr }}^{\mathrm{I}}=\mathrm{k}^{\mathrm{I}}\left(1+\mathrm{k}^{\mathrm{I}} \mathrm{D} / \mathrm{v}^{2}\right)+\mathrm{k}^{\text {probe }},\left\{\mathrm{k}^{\mathrm{I}}\right.$ is the decay rate from (a), $\mathrm{D}$ is the $\mathrm{OH}$ diffusion coefficient in He, $\mathrm{k}^{\text {probe }}$ is the decay rate for $\left[\mathrm{C}_{3} \mathrm{~F}_{6}\right]=0$ ] against $\mathrm{C}_{3} \mathrm{~F}_{6}$ concentrations, at $296 \mathrm{~K}$ and $249 \mathrm{~K}$. The lines are weighted least squares fits whose slopes give the rate constants. (c) Rate constants are plotted on a log scale against 1000/Temperature for our results at 249-296 K and those of Mcllroy and Tully at $293-489 \mathrm{~K}$. The lines are the respective Arrhenius fits.

ated $\mathrm{OH}$ in tropospheric measurements [e.g., Hard et al., 1992]. The scrubber should also have a negligible absorptivity in the vicinity of the laser wavelength, $282 \mathrm{~nm}$. The temperature and pressure dependence of its reaction with $\mathrm{OH}$ should be weak. Its efficiency to quench the $\mathrm{OH}$ fluorescence should be small. It must be safe and commercially available in high purity.

S. P. Sander has suggested [Smith and Crosley, 1990] that the halogen substituted alkenes, which form strong adducts with $\mathrm{OH}$ [e.g., Kirchner et al., 1990], would be suitable scrubbers for $\mathrm{OH}$. The adduct produced in the reaction of $\mathrm{OH}$ with some chlorinated alkenes decomposes to produce $\mathrm{Cl}$ atoms [Kirchner et al., 1990]. This makes the chlorinated alkenes unsuitable scrubbers for $\mathrm{OH}$, since $\mathrm{Cl}$ reactions with ambient hydrocarbons can generate $\mathrm{OH}$ rapidly. We select perfluoroalkenes because the strongly bound fluorine substituents inhibit radical regeneration from the adduct. Perfluorination also suppresses the $\mathrm{OH}$ fluorescence quenching efficiency of hydrocarbons significantly. Furthermore, for the fluoroalkenes the UV absorption peaks around $160 \mathrm{~nm}$, which is far enough from the $282 \mathrm{~nm}$ laser line to prevent interference from fluoroalkene photolysis. The use of tetrafluoroethene, $\mathrm{C}_{2} \mathrm{~F}_{4}$, is impractical because it polymerizes explosively. Unlike the other haloalkenes, perfluoropropene is neither toxic nor inflammable, thus making it an ideal choice. Since $\mathrm{C}_{3} \mathrm{~F}_{6}$ is a liquid with a modest vapor pressure (463-4896 torr) at atmospheric temperatures $(232-298 \mathrm{~K})$, it can be conveniently stored in a small lightweight bottle in the flight instrument. It is also readily available in high purity. We measured a negligible absorption cross section for $\mathrm{C}_{3} \mathrm{~F}_{6}$ at $282 \mathrm{~nm}$.

\section{Discharge Flow Measurements of $\mathrm{OH}+\mathrm{C}_{3} \mathrm{~F}_{6}$}

The successful implementation of $\mathrm{C}_{3} \mathrm{~F}_{6}$ as a scrubber in the Harvard $\mathrm{HO}_{\mathrm{x}}$ ER-2 instrument requires kinetic information on the $\mathrm{OH}+\mathrm{C}_{3} \mathrm{~F}_{6}$ reaction. In the absence of such measurements we estimate the rate constant to be in the range $1.5-3 \times 10^{-12}$ $\mathrm{cm}^{3}$ molecule ${ }^{-1} \mathrm{~s}^{-1}$ at room temperature from reactivity trends of other $\mathrm{OH}+$ haloalkene reactions [Abbatt and Anderson, 1991]. A slight negative activation energy $(-0.7$ to $-1.0 \mathrm{kcal} / \mathrm{mole})$ and negligible pressure dependence are anticipated. These kinetic predictions made $\mathrm{C}_{3} \mathrm{~F}_{6}$ a plausible $\mathrm{OH}$ scrubber.
The rate constant and activation energy of the $\mathrm{OH}+\mathrm{C}_{3} \mathrm{~F}_{6}$ reaction is determined using the discharge flow technique [Howard, 1979]. Briefly, $\mathrm{OH}$ is generated by the rapid reaction of $\mathrm{H}$ with excess $\mathrm{NO}_{2} ; \mathrm{H}+\mathrm{NO}_{2} \rightarrow \mathrm{OH}+\mathrm{NO}$. The $\mathrm{H}$ atoms are created by a microwave discharge of $2 \% \mathrm{H}_{2}$ in $\mathrm{He}$. The $\mathrm{OH}$ radicals are added to a well developed laminar-flow gas stream of $\mathrm{He}$ in a teflon-coated glass tube $(5 \mathrm{~cm}$ diameter). At the end of a reaction zone $\mathrm{OH}$ is detected by resonance fluorescence (sensitivity $\approx 10^{-8}$ counts $\mathrm{s}^{-1}$ molecule ${ }^{-1} \mathrm{~cm}^{3}$ ) at $308 \mathrm{~nm}$ using an $\mathrm{OH}$ lamp to excite the $0-0$ vibrational band of the $A^{2} \Sigma-X^{2} \Pi$ electronic transition.

The reactant, $\mathrm{C}_{3} \mathrm{~F}_{6}$, is added to the flow through a movable teflon-coated glass probe. All measurements are made under pseudo-first order conditions with the $\mathrm{OH}$ concentrations more than two orders of magnitude below $\mathrm{C}_{3} \mathrm{~F}_{6}$ concentrations. The $\mathrm{C}_{3} \mathrm{~F}_{6}$ (Matheson, 99.5\%) is used as received; an FTIR spectrum is taken to check its purity. The only major impurities, as reported by the manufacturer, are $\mathrm{C}_{2} \mathrm{~F}_{4}(<0.5 \%)$ and air $(<0.5 \%)$.

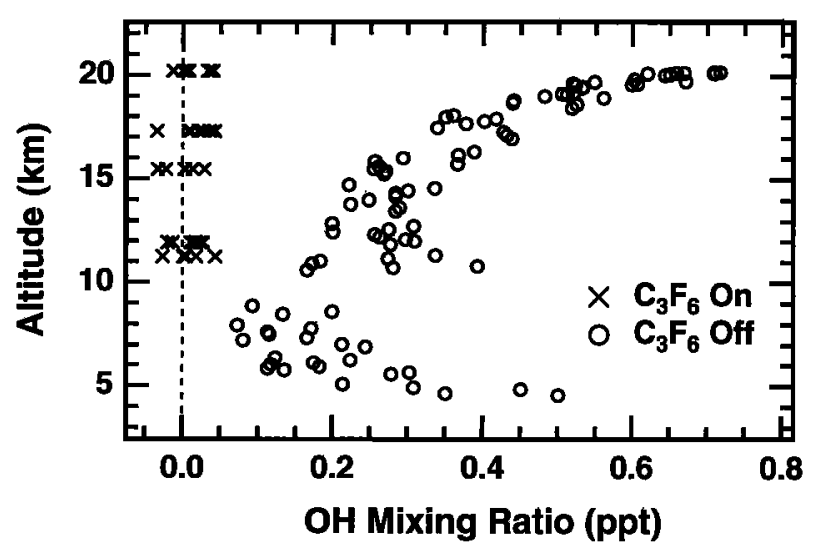

Figure 2. The $\mathrm{OH}$ mixing ratio measured on the ER-2 above NASA AMES on October 31,1995 is shown versus altitude. The open circles are measurements with $\mathrm{C}_{3} \mathrm{~F}_{6}$ off, corresponding to the ambient $\mathrm{OH}$ mixing ratio. The crosses represent the measurements with $\mathrm{C}_{3} \mathrm{~F}_{6}$ on, corresponding to the signal with all ambient $\mathrm{OH}$ removed. The scatter in the crosses is approximately equal to the precision noise of the measurement. 


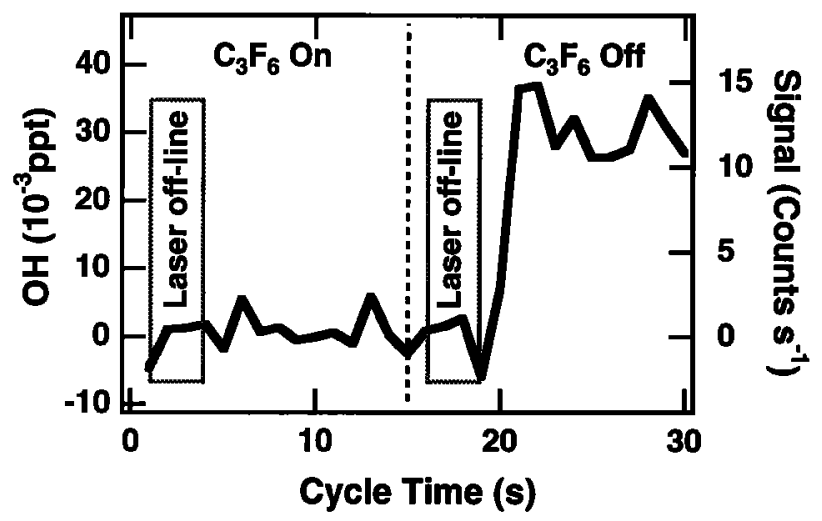

Figure 3. The $\mathrm{OH}$ signal measured from the second-story window of the Harvard Chemistry building between 10:0011:00 AM on July 7, 1995 (SZA=35). The signal is an average of 37 measurement cycles, each lasting 30 seconds. Each cycle consists of $15 \mathrm{~s}$ with and $15 \mathrm{~s}$ without $\mathrm{C}_{3} \mathrm{~F}_{6}$ addition. In each $15 \mathrm{~s}$ portion, laser scatter is measured with the laser off-resonance. Ambient $\mathrm{OH}$ is measured with the laser on-resonance and $\mathrm{C}_{3} \mathrm{~F}_{6}$ off. The detected count rate $\left(12\right.$ counts $\left.\mathrm{s}^{-1}\right)$ corresponds to a mixing ratio of $0.03 \mathrm{ppt}$ of $\mathrm{OH}$ in the flow tube.

Pseudo-first order decays are observed by fixing the $\mathrm{C}_{3} \mathrm{~F}_{6}$ concentration and monitoring the drop in the $\mathrm{OH}$ fluorescence signal as the distance between the injection point and the detection axis is increased. The concentration of $\mathrm{C}_{3} \mathrm{~F}_{6}$ in the flow tube is determined by measuring the rate of pressure drop in a glass reservoir of known volume. The reaction temperature is controlled by circulating cooled ethanol in the flow tube jacket. Pressure is measured at the center of the reaction zone and flowrates are measured by calibrated flowmeters. These are used to determine the bulk velocity from which we infer reaction time using the plug-flow approximation.

The experimental pseudo-first order decays are corrected for axial diffusion $(<3 \%)$ and probe loss $\left(<4 \mathrm{~s}^{-1}\right)$. A typical series of corrected $\mathrm{OH}$ decays for various $\mathrm{C}_{3} \mathrm{~F}_{6}$ concentrations at 296 $\mathrm{K}$ and 2.8 torr is displayed in Figure $1 \mathrm{a}$. The plot of the corrected decays against the $\mathrm{C}_{3} \mathrm{~F}_{6}$ concentration is linear for all temperatures (e.g., Figure 1b). At room temperature many such observations are made at several pressures ranging from 1.7 to 3.8 torr. A weighted least squares fit of these decays yields a bimolecular rate constant of $(2.1 \pm 0.2) \times 10^{-12} \mathrm{~cm}^{3}$ molecule ${ }^{-1}$ $\mathrm{s}^{-1}$ at $296 \mathrm{~K}$, independent of pressure. The error estimate includes known uncertainties. A weighted least squares analysis of the Arrhenius behavior of numerous measurements at four temperatures ( 29 at $296 \mathrm{~K}, 11$ at $281 \mathrm{~K}, 9$ at $264 \mathrm{~K}, 8$ at $249 \mathrm{~K}$ ) results in a temperature dependent rate constant of $(6.0 \pm 0.8) \times$ $10^{-13} \exp [(370 \pm 40) / \mathrm{T}] \mathrm{cm}^{3}$ molecule $\mathrm{e}^{-1} \mathrm{~s}^{-1}$. The temperature dependent rate constants are shown in the Arrhenius plot in Figure 1c; the reported $2 \sigma$ error limits include systematic errors.

A flash photolysis study of this reaction at higher temperatures (293-831 K) and pressures (75-750 torr) has been reported by McIlroy and Tully [1993]. Their rate constant measurement of $(2.26 \pm 0.12) \times 10^{-12} \mathrm{~cm}^{3}$ molecule $^{-1} \mathrm{~s}^{-1}$ at 75 torr and $293 \mathrm{~K}$ agrees with our low pressure observations. They also do not observe a pressure dependence in the 75 to 750 torr pressure range. Their conclusion that the high pressure limit is reached at a pressure below 75 torr is consistent with our observations. McIlroy and Tully report a highly structured Arrhenius plot with a negative activation energy below $489 \mathrm{~K}$, and a positive activation energy above $656 \mathrm{~K}$. This indicates a transition in the mechanism from an addition reaction at low temperatures to an addition/elimination pathway at higher temperatures. They show that the HO- $\mathrm{C}_{3} \mathrm{~F}_{6}$ adduct is stable with a long lifetime near room temperature. Their derived Arrhenius expression for data taken between $293-489 \mathrm{~K},(9.95 \pm 0.64) \times 10^{-13}$ $\exp [(245 \pm 22) / \mathrm{T}] \mathrm{cm}^{3}$ molecule $\mathrm{e}^{-1} \mathrm{~s}^{-1}$, is in good agreement with our result, considering that different techniques and temperature regimes are used (Figure 1c).

\section{Chemical modulation of ambient $\mathrm{OH}$}

Stratosphere and Upper Troposphere: Extrapolating the measurements reported here to $230 \mathrm{~K}$ (lower stratospheric temperature), we estimate that for $\left[\mathrm{C}_{3} \mathrm{~F}_{6}\right]$ of $1-4 \times 10^{14}$ molecules $\mathrm{cm}^{-3}$ the e-folding time for $\mathrm{OH}$ removal will be $3.2-0.8 \mathrm{~ms}$. The reaction time available in the ER-2 $\mathrm{HO}_{\mathrm{x}}$ instrument is typically $10 \mathrm{~ms}$. This is long enough for $\mathrm{OH}$ to be removed from the ambient air before reaching the detection volume. However, the time scale for $\mathrm{OH}$ removal by $\mathrm{C}_{3} \mathrm{~F}_{6}$ is considerably longer than the excitation laser pulse (10 ns) and has a negligible effect on the $\mathrm{OH}$ generated in the detection region. The mixing ratio of $\mathrm{C}_{3} \mathrm{~F}_{6}$ used is too small to affect either the $\mathrm{OH}$ fluorescence yield or the $\mathrm{O}\left({ }^{1} \mathrm{D}\right)$ lifetime.

The ER-2 $\mathrm{HO}_{\mathrm{x}}$ instrument detects the fluorescence signal from $\mathrm{OH}$ excited by a tunable laser via the $Q_{1}(2)$ transition of the ${ }^{2} \Sigma^{+}(v=1) \leftarrow{ }^{2} \Pi(v=0)$ band at $282 \mathrm{~nm}$. OH signals are obtained with the laser tuned on-resonance with the $Q_{1}(2)$ transition, and background signals are measured with the laser tuned off-resonance. In the absence of laser generated $\mathrm{OH}$, the addition of sufficient amounts of $\mathrm{C}_{3} \mathrm{~F}_{6}$ will remove all ambient $\mathrm{OH}$ and reduce the fluorescence signal to background levels. If laser generated $\mathrm{OH}$ is present, the addition of $\mathrm{C}_{3} \mathrm{~F}_{6}$ will reduce the fluorescence signal to some level above background. Calculations using the rate constant, the sampling duct crosssection, and the flow velocity in the instrument ensure that the addition of $\mathrm{C}_{3} \mathrm{~F}_{6}$ (injected through a $70 \mathrm{sccm}$ frit) at $\left[\mathrm{C}_{3} \mathrm{~F}_{6}\right] \approx 2$ $\times 10^{14}$ molecules $\mathrm{cm}^{-3}$ in the sampling duct, will reduce the ambient $[\mathrm{OH}]$ by 5 e-folds before the sampled air reaches the detection volume in the instrument.

This chemical modulation scheme was initially implemented in the Harvard $\mathrm{HO}_{\mathrm{x}}$ ER-2 instrument during the SPADE (Stratospheric Photochemistry and Dynamics Expedition) campaign in the fall of 1992. In situ lower stratospheric experiments showed that $\mathrm{OH}$ LIF signals decay to background levels when $\mathrm{C}_{3} \mathrm{~F}_{6}$ is added to the sampled air, demonstrating the absence of laser generated $\mathrm{OH}$ [Wennberg et al., 1994b]. More recently, this technique has been implemented to verify the absence of laser generated $\mathrm{OH}$ in the upper troposphere. These measurements were made possible by the new flight profile of the ER-2, designed for obtaining upper tropospheric data. The flight included several constant altitude legs lasting 30 minutes each at altitudes between 11 and $20 \mathrm{~km}$. In situ data shown in Figure 2 clearly demonstrate the absence of laser generated $\mathrm{OH}$ at altitudes above $10 \mathrm{~km}$. These results are consistent with the absence of signal seen during nighttime (SZA > 110) when [OH] is expected to be very low.

Data below $10 \mathrm{~km}$ are not available for the $\mathrm{C}_{3} \mathrm{~F}_{6}$ addition because the ER-2 did not perform cruise legs below this altitude. However, for the data shown in Figure 2, we estimate that the signal due to laser generated $\mathrm{OH}$ below $10 \mathrm{~km}$ amounts to less than 0.01 ppt. This is based on the analysis presented in Shirinzadeh et al. [1987] extrapolated to the conditions of our measurements $\left(\mathrm{O}_{3}<50 \mathrm{ppb} ; \mathrm{H}_{2} \mathrm{O}<600 \mathrm{ppm}\right.$; laser pulse energy 
$<1 \mu \mathrm{J}$; laser beam diameter $\approx 1.5 \mathrm{~mm}$ in the non-overlapping White cell). At higher $\mathrm{O}_{3}$ concentrations or higher $\mathrm{H}_{2} \mathrm{O}$ mixing ratios, however, we do expect significant interference, and thus addition of $\mathrm{C}_{3} \mathrm{~F}_{6}$ will be useful to quantify the spurious signal.

Tropospheric Boundary Layer: The detection of $\mathrm{OH}$ by LIF in the lower troposphere and boundary layer requires careful investigation of laser generated $\mathrm{OH}$ because the mixing ratio of $\mathrm{OH}$ is low $(<0.1 \mathrm{ppt})$; thus, even small production of laser generated $\mathrm{OH}$ can result in significant error. The most promising groundbased technique for the measurement of $\mathrm{OH}$ with LIF is the expansion of ambient air through an orifice into a low pressure detection region [e.g., Hard et al., 1992; Stevens et al., 1994]. This technique has the advantage of decreasing the concentrations of species that contribute to the non-resonant fluorescence signal $\left(\mathrm{SO}_{2}, \mathrm{CH}_{2} \mathrm{O}\right)$ and of those that might contribute to laser generated $\mathrm{OH}\left(\mathrm{O}_{3}, \mathrm{H}_{2} \mathrm{O}\right.$, hydrocarbons). In addition, the quenching rates of $\mathrm{OH}$ in the low-pressure sampling region are two orders of magnitude lower than at ambient pressures, thus the fluorescence quantum yield is accordingly higher. The disadvantage of this technique is the loss of $\mathrm{OH}$ on the orifice or on the walls of the low pressure region that has to be calibrated in the laboratory.

The interferences generated with the LIF technique in the boundary layer were examined by measuring $\mathrm{OH}$ from the second-story window of the Harvard Chemistry building. The air was sampled through an $0.23 \mathrm{~cm}$ diameter orifice mounted on the end of a $8 \mathrm{~cm}$ diameter, $100 \mathrm{~cm}$ long, halocarbon-wax coated flow tube attached to the duct of the $\mathrm{HO}_{\mathrm{x}}$ instrument. Approximately $50 \mathrm{slm}$ were pulled through the orifice using a large roots pump, resulting in a flow of $30 \mathrm{~m} / \mathrm{s}$ at 3.5 torr. $\mathrm{C}_{3} \mathrm{~F}_{6}$ was added to the flow through a $70 \mathrm{sccm}$ frit $\left(\left[\mathrm{C}_{3} \mathrm{~F}_{6}\right] \approx\right.$ $10^{14}$ molecules $\mathrm{cm}^{-3}$ ) at the end of the flow tube. By adding $\mathrm{OH}$ generated by a hot filament ( $>1 \mathrm{ppt}$ ) to the flow we verified that this amount of $\mathrm{C}_{3} \mathrm{~F}_{6}$ completely removed ambient $\mathrm{OH}$ before reaching the detection region. By adding a large amount of $\mathrm{O}_{3}$ $\left(\gg 1 \mathrm{ppm}\right.$ ) to the flow we confirmed that the added $\mathrm{C}_{3} \mathrm{~F}_{6}$ did not affect the laser generated $\mathrm{OH}$ signal by more than a few percent.

Figure 3 shows the $\mathrm{OH}$ signal measured with $\mathrm{C}_{3} \mathrm{~F}_{6}$ addition on and off. The signal with the $\mathrm{C}_{3} \mathrm{~F}_{6}$ addition on is less than 1 count $\mathrm{s}^{-1}(\approx 0.003 \mathrm{ppt}$ of $\mathrm{OH})$. The lack of an observed interference is consistent with the analysis presented in Shirinzadeh et al. [1987]. Extrapolating to the conditions of this study $\left(\mathrm{O}_{3}=\right.$ $50 \mathrm{ppb}$; Relative Humidity $=55 \%$; $\mathrm{T}=304 \mathrm{~K}$; laser pulse energy $\approx 0.5 \mu \mathrm{J}$; laser beam diameter $\approx 1.5 \mathrm{~mm}$ in the non-overlapping White cell), we expect to observe approximately $0.002 \mathrm{ppt}$ of laser generated $\mathrm{OH}$. The amount of laser generated $\mathrm{OH}$ is expected to increase linearly with both laser pulse energy, and the $\mathrm{O}_{3}$ and $\mathrm{H}_{2} \mathrm{O}$ mixing ratios. Under heavily polluted conditions or with significantly higher laser power, we would expect to see a significant interference; thus, $\mathrm{C}_{3} \mathrm{~F}_{6}$ addition should be used to ensure an accurate ambient $\mathrm{OH}$ measurement.

The removal of $\mathrm{OH}$ by $\mathrm{C}_{3} \mathrm{~F}_{6}$ is inappropriate when high concentrations of $\mathrm{NO}$ are present. For instance, $\mathrm{HO}_{2}$ is measured by conversion to $\mathrm{OH}$ with the addition of NO. We see a large amount of $\mathrm{OH}$ upon adding $\mathrm{C}_{3} \mathrm{~F}_{6}$ during our boundary layer $\mathrm{HO}_{2}$ measurements. The presence of NO enables reactions that regenerate OH rapidly [Donahue et al., 1996], thus disabling the $\mathrm{C}_{3} \mathrm{~F}_{6}$ scrubbing mechanism.

\section{Conclusions}

Perfluoropropene is an ideal reagent to remove $\mathrm{OH}$ from sampled air to monitor any photolytic intereference in LIF measurements of atmospheric $\mathrm{OH}$. We measure rate constants for $\mathrm{OH}+\mathrm{C}_{3} \mathrm{~F}_{6}$ between $249-296 \mathrm{~K}$ to determine the amount of $\mathrm{C}_{3} \mathrm{~F}_{6}$ required to completely remove ambient $\mathrm{OH}$ from the detection region of the Harvard ER-2 $\mathrm{HO}_{\mathrm{x}}$ instrument. In situ experiments using $\mathrm{C}_{3} \mathrm{~F}_{6}$ to chemically modulate $\mathrm{OH}$ in the ambient air demonstrate the lack of interference from laser generated $\mathrm{OH}$ in lower stratospheric and tropospheric $\mathrm{OH}$ measurements. We demonstrate that laser excitation of the ${ }^{2} \Sigma^{+}(v=1) \leftarrow{ }^{2} \Pi(v=0)$ transition using high pulse repetition rates and low peak power can be combined with chemical modulation to make reliable and sensitive $\mathrm{OH}$ measurements in the boundary layer.

Acknowledgments. We thank NASA's Upper Atmospheric Research and Atmospheric Effects of Aviation Programs for support.

\section{References}

Abbatt, J. P. D. and J. G. Anderson, High-pressure discharge flow kinetics and frontier orbital mechanistic analysis of $\mathrm{OH}+\mathrm{CH}_{2} \mathrm{CCl}_{2}$, cis$\mathrm{CHClCHCl}$, trans-CHClCHCl, $\mathrm{CFClCF}_{2}$, and $\mathrm{CF}_{2} \mathrm{Cl}_{2} \rightarrow$ products, $J$. Phys. Chem., 95, 2382-2390, 1991.

Albritton, D. L., F. C. Fehsenfeld, and A. F. Tuck, Instrumental requirements for global atmospheric chemistry, Science, 250, 75-81, 1990.

Crosley, D. R., The measurements of $\mathrm{OH}$ and $\mathrm{HO}_{2}$ in the atmosphere, $J$. Atmos. Sci., 52, 3299-3314, 1995.

Crutzen, P. J., A discussion of the chemistry of some minor constituents in the stratosphere and troposphere, Pure Appl. Geophys., 106, 1385$1399,1973$.

Donahue, N. M., K. L. Demerjian, and J. G. Anderson, Reaction modulation spectroscopy: A new approach to quantifying reaction mechanisms, J. Phys. Chem., in press, 1996.

Hard, T. M., A. A. Mehrabzadeh, C. Y. Chan, and R. J. O'Brien, FAGE measurements of tropospheric HO with measurements and model of interferences, J. Geophys. Res., 97, 9795-9817, 1992.

Howard, C. J., Kinetic measurements using flow tubes, J. Phys. Chem., 83, 3-9, 1979.

Jucks, K. W., et al., Ozone production and loss rate measurements in the middle stratosphere, J. Geophys. Res., in press, 1996.

Kirchner, K., D. Helf, P. Ott, and S. Vogt, The reaction of $\mathrm{OH}$ radicals with 1,1-di-, tri- and tetrachloroethylene, Ber. Bunsenges. Phys. Chem., 94, 77-83, 1990.

Mcllroy, A. and F. P. Tully, Kinetic study of $\mathrm{OH}$ reactions with perfluoropropene and perfluorobenzene, J. Phys. Chem., 97, 610-614, 1993.

Shirinzadeh, B., C. C. Wang, and D. Q. Deng, Pressure dependence of ozone interference in the laser fluorescence measurements of $\mathrm{OH}$ in the atmosphere, Appl. Optics, 26, 2102-2105, 1987.

Smith, G. P. and D. R. Crosley, A photochemical model of ozone interference effects in laser detection of tropospheric $\mathrm{OH}, J$. Geophys. Res., 95, 16427-16442, 1990.

Stevens, P. S., J. H. Mather, and W. H. Brune, Measurement of tropospheric $\mathrm{OH}$ and $\mathrm{HO}_{2}$ by laser-induced fluorescence at low pressure, J. Geophys. Res., 99, 3543-3557, 1994.

Stimpfle, R. M. and J. G. Anderson, In situ detection of $\mathrm{OH}$ in the lower stratosphere with a balloon borne high repetition rate laser system, Geophys. Res. Lett., 15, 1503-1506, 1988.

Wennberg, P. O., et al., Removal of stratospheric $\mathrm{O}_{3}$ by radicals: In situ measurements of $\mathrm{OH}, \mathrm{HO}_{2}, \mathrm{NO}, \mathrm{NO}_{2}, \mathrm{ClO}$, and BrO, Science, 266, 398-404, 1994a.

Wennberg, P. O., et al., Aircraft-borne, laser-induced fluorescence instrument for the in situ detection of hydroxyl and hydroperoxyl radicals, Rev. Sci. Instrum., 65, 1858-1876, 1994b.

M. K. Dubey, Mol. Phys. Lab., SRI International, 333 Ravenswood Avenue, Menlo Park, CA 94025. (e-mail: dubey@mplvax.sri.com)

T. F. Hanisco, P. O. Wennberg, J. G. Anderson, Dept. of Chemistry, Harvard University, 12 Oxford Street, Cambridge, MA 02138.

(Received July 17, 1996; revised September 13, 1996; accepted September 19, 1996.) 